\title{
The in vitro fermentation of maize stover as affected by faecal bacteria obtained from ungulates
}

\author{
F.N. Fon ${ }^{\#}$ \& I.V. Nsahlai \\ \#Animal and Poultry Science, University of KwaZulu-Natal, P/Bag X01, Scottsville 3209, South Africa
}

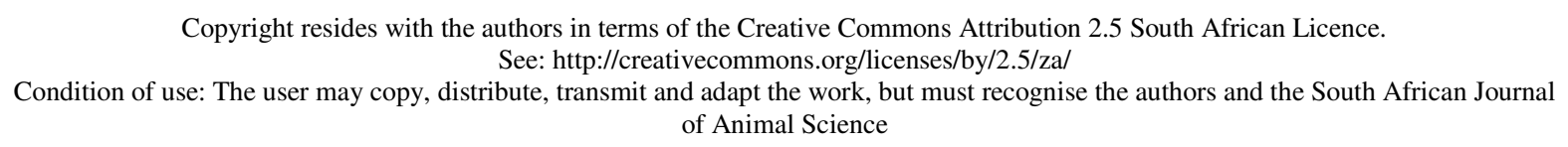

\begin{abstract}
The effect of different inoculum sources, obtained from the faeces of ungulates, i.e. horses $(\mathrm{H})$, wildebeest (WB) and zebra (ZB) and combinations of inoculum sources on the fermentation of maize stover (MS) was investigated. Combined sources (CS) were: (1) H+WB, (2) H+ZB, (3) WB+ZB and (4) $\mathrm{H}+\mathrm{WB}+\mathrm{ZB}$. Fresh faecal inocula were cultured in the laboratory on MS and lucerne (mixed in $1: 1$ ratio) with salivary buffer for $72 \mathrm{~h}$ at $38^{\circ} \mathrm{C}$ prior to application as an inoculum or extraction of crude protein (CPZ) for enzyme assays. Crude protein was precipitated using $60 \%$ ammonium sulphate and analyzed for exocellulase, endocellulase and hemicellulase specific activities ( $\mu$ g reducing sugar/mg CPZ). An in vitro fermentation study was done by transferring $33 \mathrm{~mL}$ of laboratory cultured faecal inoculum into $67 \mathrm{~mL}$ of salivary buffer containing $1 \mathrm{~g}$ MS and incubating for $72 \mathrm{~h}$ at $38^{\circ} \mathrm{C}$. Exocellulase specific activities differed among the seven inoculum sources. Exocellulase activity ranked the different microbial sources according to their fibrolytic potential as follows: $1>2>4>\mathrm{H}>\mathrm{ZB}>\mathrm{WB}>3$. Total gas, true degradability (TD), microbial yield and total short chain fatty acids (SCFA) were higher in the CS than in the individual systems. Systems 1 and 3 had the highest TD (714mg/g CPZ) and total SCFA (680 mg/g CPZ), respectively. True degradability, total gas, total SCFA, partitioning factor and degradability efficiency ranked the microbial ecosystems according to their fibrolytic potential as follows: $3>1>4>\mathrm{WB}>2>\mathrm{ZB}>\mathrm{H}$. Inoculum sources differed in fibrolytic digestion, with microbes from CS (1) and (4) proving to be the best. Further investigation is essential towards using inoculums sources as possible feed additives in ruminants.
\end{abstract}

Keywords: Faecal digesta, fibrolytic competence

\#Corresponding author: Fonf@ukzn.ac.za, fabiannde@yahoo.co.uk

\section{Introduction}

Low quality forages affects animal performance negatively because of their low digestibility and voluntary feed intake (Van Ackeren et al., 2009). Low digestibility is partly a consequence of the forage property (Wei et al., 2009), host animal adaptation and partly associated with the extent of microbial activity in the rumen and the caecum. Forage type, microbial species and evolution have been the major focus of most studies (Bänziger et al., 2006). Although forage type is still a major problem, the advancement of plant biotechnology has allowed for the modification of plants through genetic engineering and producing forages of higher nutritive values. In the tropics, herbivores still depend largely on low quality roughages and agricultural crop residues which are lower in both fermentable carbohydrate and protein content than temperate forages (Wanapat et al., 2009). Fermentation in the rumen and hindgut depends largely on the efficiency of microbes of herbivores. Different studies have shown that microbes from the same or different herbivore species grazing on the same or different fields may vary in their ability to ferment fibre (Kenters et al., 2011). Some of these studies reported an increase in weight gain, SCFA, milk production or cellulolytic enzymes activity (Gado et al., 2009) when supplemented with cellulolytic microbes or enzymes.

Application of cellulolytic microbes might have an advantage over enzyme-supplementation if they can survive degradation by rumen proteases; this implies cellulolytic enzyme supply from microbes will be continuous. It is, however, yet to be determined whether microbes from these ecosystems can co-exist in the 
same medium and if such co-existence can confer positive synergism on fibrolysis. At present there is very limited information monitoring the synergistic activity of bacteria obtained from two or more rumen environments. Wanapat (2001), Vaithiyanathan et al. (2005) and Dominguez Bello \& Escobar (1997) described microbe survival for up to 14 days. Therefore, the objective of this study is to determine the effect of combined fibrolytic activities obtained from two or more ungulates' (horse, wildebeest or zebra) microbial ecosystems.

\section{Materials and methods}

Animals used were (i) horses (H) (Equus caballus) from the Ukulinga Research farm, University of KwaZulu Natal,(ii) zebra (ZB) (Equus quagga boehmi) and (iii) wildebeest (WB) (Connochaetes taurinus) (WB) from the Tala Game Reserve, Umbumbulu, KwaZulu-Natal. The ZB and WB were grazing in an open field where Pennisetum clandestinum (Kikuyu grass) and standing grass hay were dominant. Horses grazed in an open field with kikuyu grass as standing hay, ryegrass, veld and red grasses were also dominant. They were supplemented with grass hay while in pens. Faecal samples (three samples from each species) were collected in winter from mature $\mathrm{H}, \mathrm{WB}$ and $\mathrm{ZB}$ within 2 min of defecation with no preference to sex. Samples were transferred into a $\mathrm{CO}_{2}$ flushed, thermo flask $\left(38^{\circ} \mathrm{C}\right)$. Three animals of each type were used on three different collection days. After sampling, each sample type was divided into three replicates for each incubation day.

Approximately $300 \mathrm{~g}$ of faeces was mixed with $300 \mathrm{~mL}$ of warm salivary buffer (Ouda \& Nsahlai, 2009) and mixed thoroughly before squeezing through four layers of cheese cloth to produce faecal fluid (FF). Since the microbes in the faeces are anaerobic, this process was conducted in the shortest possible time (ca. $15 \mathrm{~min})$ to minimize their exposure to oxygen. Faecal filtrate $(198 \mathrm{~mL})$ for each individual system $(\mathrm{H}$, WB or ZB) was pipetted into $402 \mathrm{~mL}$ of salivary buffer (flushed with $\mathrm{CO}_{2}$ and placed in an incubator to equilibrate to $39^{\circ} \mathrm{C}$ for $1 \mathrm{~h}$ ) containing $6 \mathrm{~g}$ of a $1: 1$ mixture of lucerne and maize stover milled through a 1$\mathrm{mm}$ sieve. For the combinations $\mathrm{H}+\mathrm{WB}, \mathrm{H}+\mathrm{ZB}, \mathrm{WB}+\mathrm{ZB}$ and $\mathrm{H}+\mathrm{WB}+\mathrm{ZB}$, fresh inocula were mixed in equal proportions before culturing. The culture samples were flushed with $\mathrm{CO}_{2}$ and incubated for $72 \mathrm{~h}$ at $38.5^{\circ} \mathrm{C}$ in airtight Duran ${ }^{\circledR}$ bottles. After $72 \mathrm{~h}$, the different cultured FF was used as inocula for in vitro fermentation or extraction of crude protein for cellulase activities. The activeness of these microbial ecosystems was determined by monitoring $\mathrm{pH}$ changes.

Crude protein was extracted from cultured filtrate using $60 \%\left(\mathrm{NH}_{4}\right)_{2} \mathrm{SO}_{4}$, dialyzed, concentrated using polyethylene glycol 20000 and concentration determined by Bradford assay. Exocellulase, endocellulase and hemicellulase activities were assayed using carboxylmethyl cellulose sodium salt from FLUKA Bichemica (Germany), crystalline cellulose from ALDRICH® (Germany) and xylan from beech wood from SIGMA (USA) as substrates, respectively, and reducing sugars measured by Dinitrosalicylic method (Fon, 2006). Each enzyme assay was replicated three times with four pseudo repeats. Enzyme specific activity was defined as $\mu \mathrm{g}$ of reducing sugar $/ \mathrm{mg}$ crude protein.

For in vitro digestibility, an automated gas production method using computerized pressure transducer system, similar as described by Pell \& Schofield (1993), was used. Inocula were from H, WB, ZB and combination cultures. Each inoculum $(33 \mathrm{~mL})$ was transferred into $67 \mathrm{~mL}$ of salivary buffer containing $1 \mathrm{~g}$ maize stover $(3 \mathrm{~mm})$ and incubated for $72 \mathrm{~h}$ at $38.5{ }^{\circ} \mathrm{C}$. Substrate incubation with each inoculum type was replicated three times with 3 - 4 pseudo repeats. Gas and the rate of gas production were measured by fitting the raw data in the model described by Campos et al. (2004). The total gas produced from MS fermentation (GP), the time taken to produce half the gas $\left(T_{1 / 2}\right)$, the gas at the point of inflection $(\mu)$ and the overall rate of MS fermentation (C) were measured. After incubation, the residue was used to determine, apparent and true degradability (TD) and microbial yield while the filtrate was used to determine total short chain fatty acids (SCFA) using gas chromatography as described by Cottyn \& Boucque (1968). Partitioning factor $(\mathrm{PF}=$ TD/GP) was calculated as described by Ouda \& Nsahlai (2009). The results from cellulase enzyme activities, MS degradability and gas estimates derived from fermentation were subjected to analysis of variance (ANOVA) using the general linear model of SAS. The model was: $Y_{i j}=\mu+T_{i}+e_{i j}$ (Where $Y_{i j}$ is the individual observation, $\mu$ is the overall mean, $T_{i}$ is the effect of the treatment and $\mathrm{e}$ is the random variation). 


\section{Results and Discussion}

Exocellulase, endocellulase and hemicellulase specific activities differed $(P<0.001)$ among the seven microbial ecosystems (Table 1). Hemicellulolytic activity was highest in CS 4, followed by 2 and $\mathrm{H}$. H and ZB had the third highest specific activity compared to CS 1 and 3, while the least hemicellulolytic activity was observed in WB. This implies that microbial synergism in CS had a net positive effect on xylan hydrolysis with higher values observed in CS 4 and 1 than in the IS. Only CS 4 had a much higher endocellulase specific activity compared to the other CS. The highest endocellulolytic activity was observed in $\mathrm{CS} 4$, while $\mathrm{H}$ and $\mathrm{ZB}$ were the second highest. All the other systems demonstrated a moderate endocellulolytic activity except for CS 2 and WB, which showed the lowest activities. The highest exocellulase specific activities were observed in CS 1,2 and 4. The $\mathrm{H}$ demonstrated the second highest exocellulase specific activity, while the least was observed in WB. This implies that the effect of CS on amorphous cellulose solubilization was only prominent in CS 4. Exocellulase specific activities in CS were generally higher than those of the IS. Although the exact explanation of the fibrolytic enhancement of these ecosystems is not very clear, it is possible that mixing microbial inoculum from different animal species might have introduce microbes of higher fibrolytic potential, which can compete and survive in the new ecosystem. The survival of such microbes implies an increase in potent exocellulases; hence, an increase in fibre breakdown.

Table 1 Monitoring the specific activities of exocellulase, endocellulase and xylanase of crude protein extracts from seven in vitro microbial ecosystems

\begin{tabular}{|c|c|c|c|c|c|c|c|c|c|}
\hline \multirow{3}{*}{$\begin{array}{l}\text { Enzyme specific activity } \\
\text { ( } \mu \text { g reducing } \\
\text { sugar/mg CPZ) }\end{array}$} & \multicolumn{9}{|c|}{ Inocula sources } \\
\hline & \multirow{2}{*}{$\mathrm{H}$} & \multirow{2}{*}{ WB } & \multirow{2}{*}{$\mathrm{ZB}$} & \multicolumn{4}{|c|}{ Combined sources (CS) } & \multirow{2}{*}{ SEM } & \multirow{2}{*}{$P$-value } \\
\hline & & & & 1 & 2 & 3 & 4 & & \\
\hline Hemicellulase & $98.2^{\mathrm{c}}$ & $57.3^{\mathbf{a b}}$ & $88.8^{\mathrm{d}}$ & $81.4^{\mathrm{a}}$ & $104.5^{\mathrm{d}}$ & $68.5^{\mathrm{ab}}$ & $183^{\text {be }}$ & 2.6 & 0.001 \\
\hline Endocellulase & $92.7^{\mathrm{b}}$ & $72.5^{\mathrm{d}}$ & $89.2^{\mathrm{b}}$ & $87.7^{\mathrm{b}}$ & $77.6^{\mathrm{c}}$ & $80.5^{\mathrm{c}}$ & $108.5^{\mathrm{a}}$ & 1.9 & 0.001 \\
\hline Exocellulase & $141.8^{\mathrm{b}}$ & $90.5^{\mathrm{d}}$ & $107.1^{\mathrm{c}}$ & $163.1^{\mathrm{a}}$ & $162.6^{\mathrm{a}}$ & $98.1^{\mathrm{cd}}$ & $160.9^{\mathrm{a}}$ & 4.1 & 0.001 \\
\hline
\end{tabular}

$\mathrm{H}$ - horse; WB - wildebeest; ZB - zebra; CS 1 = H+WB; CS $2=\mathrm{H}+\mathrm{ZB}$; CS 3 = WB+ZB; CS $4=\mathrm{H}+\mathrm{WB}+\mathrm{ZB}$.

$\mathrm{CPZ}$ - crude protein extract for enzyme assay.

$\mathrm{a}, \mathrm{b}, \mathrm{c}, \mathrm{d}, \mathrm{e}$ : Values with different superscripts in the same row differ at $P<0.05$.

Apparent (APD) and true (TD) degradability differed $(P<0.001)$ among herbivore microbial ecosystems (Table 2) due to ecosystem variation. The large difference between APD and TD was associated to microbial attachment to fibrous matter. The highest APD value for MS was observed in CS 1 while systems WB, 4 and 3 were intermediate when compared to systems H, ZB and N2. The TD was highest in CS 1 and intermediate in 3, WB, 4 and 2 when compared to $\mathrm{H}$ and $\mathrm{ZB}$ microbial ecosystems. There was a significant difference $(P<0.001)$ in GP among the seven microbial ecosystems when incubated with MS. Combine systems 3 and 4 recorded the highest GP, followed by CS 1 and WB with intermediate values when compared to CS 2, ZB and H with the lowest GP. Both TD and GP from CS showed that, combining IS can improve digestibility; this is similar to the results obtained by Wanapat (2001). Microbial yield (MY) was highest $(P<0.05)$ in CS 2 and intermediate in $4, \mathrm{ZB}$ and 3. These are clear indications that in vitro transinoculation is possible and can increase microbial population which may increase fibrolytic activities (Wanapat, 2001). The rate (C) of MS fermentation was not significantly different among the microbial ecosystems but the results show that $\mathrm{C}$ tended to be higher in $\mathrm{ZB}$ compared to the other systems. The time taken to produce half GP $\left(\mathrm{T}_{1 / 2}\right)$ was longer $(P<0.01)$ for the combined systems $(\mathrm{CS})$ than in the individual systems (IS). Gases produced at the point of inflection $(\mu)$ were similar among the microbial systems. The PF (one of many parameters used in evaluating the nutritive values of feed (Ouda \& Nsahlai, 2009)) was 
Table 2 In vitro fermentation of maize stover as affected by different microbial ecosystems

\begin{tabular}{|c|c|c|c|c|c|c|c|c|c|}
\hline \multirow{2}{*}{$\begin{array}{l}\text { Digestibility } \\
\text { Parameters }\end{array}$} & \multicolumn{7}{|c|}{ Inocula sources } & \multirow[b]{2}{*}{ SEM } & \multirow[b]{2}{*}{$P$-value } \\
\hline & $\mathrm{H}$ & WB & $\mathrm{ZB}$ & CS 1 & CS 2 & CS 3 & $\mathrm{CS} 4$ & & \\
\hline APD $(\mathrm{mg} / \mathrm{g})$ & $356^{\mathrm{cd}}$ & $457^{\mathrm{ab}}$ & $324^{\mathrm{d}}$ & $485^{\mathrm{a}}$ & $316^{\mathrm{d}}$ & $430^{\mathrm{ab}}$ & $402^{\mathrm{bc}}$ & 9.7 & 0.001 \\
\hline $\mathrm{TD}(\mathrm{mg} / \mathrm{g})$ & $584^{\mathrm{c}}$ & $679^{\mathrm{b}}$ & $589^{c}$ & $714^{\mathrm{a}}$ & $606^{\mathrm{c}}$ & $680^{\mathrm{b}}$ & $671^{\mathrm{b}}$ & 4.2 & 0.001 \\
\hline MY (mg/g) & $228^{\mathrm{b}}$ & $222^{\mathrm{b}}$ & $265^{\mathrm{ab}}$ & $229^{\mathrm{b}}$ & $290^{\mathrm{a}}$ & $250^{\mathrm{ab}}$ & $269^{\mathrm{ab}}$ & 9.0 & 0.05 \\
\hline $\mathrm{GP}(\mathrm{mL} / \mathrm{g})$ & $97^{\mathrm{c}}$ & $135^{\mathrm{ab}}$ & $102^{\mathrm{c}}$ & $132^{\mathrm{b}}$ & $117^{\mathrm{bc}}$ & $146^{\mathrm{a}}$ & $148^{\mathrm{a}}$ & 3.7 & 0.001 \\
\hline $\mathrm{C}(/ \mathrm{h})$ & 0.022 & 0.02 & 0.025 & 0.021 & 0.02 & 0.02 & 0.02 & 0.001 & 0.07 \\
\hline $\mathrm{T} 1 / 2(\mathrm{~h})$ & $24.6^{\mathrm{bc}}$ & $27.3^{\mathrm{b}}$ & $21.8^{\mathrm{c}}$ & $28.3^{\mathrm{ab}}$ & $27.5^{\mathrm{ab}}$ & $28.9^{\mathrm{ab}}$ & $30.6^{\mathrm{a}}$ & 0.7 & 0.01 \\
\hline$\mu(\mathrm{mL} / \mathrm{h})$ & 2.1 & 2.6 & 2.5 & 2.7 & 2.3 & 2.9 & 2.8 & 0.1 & 0.08 \\
\hline $\mathrm{PF}$ & $6^{\mathrm{a}}$ & $5^{\mathrm{ab}}$ & $5.8^{\mathrm{ab}}$ & $5.6^{\mathrm{ab}}$ & $5.2^{\mathrm{ab}}$ & $4.7^{\mathrm{b}}$ & $4.6^{\mathrm{b}}$ & 0.2 & 0.01 \\
\hline Total SCFA & $29.12^{\mathrm{c}}$ & $46.81^{\mathrm{abc}}$ & $30.99^{\mathrm{bc}}$ & $47.42^{\mathrm{abc}}$ & $56.74^{\mathrm{b}}$ & $71.54^{\mathrm{a}}$ & $33.02^{\mathrm{bc}}$ & 3.34 & 0.001 \\
\hline
\end{tabular}

APD - apparent degradability; TD - true degradability; MY - microbial yield; H - horse; WB - wildebeest; ZB - zebra. Combine inocula sources $(\mathrm{CS}): 1=\mathrm{H}+\mathrm{WB}, 2=\mathrm{H}+\mathrm{ZB}, 3=\mathrm{WB}+\mathrm{ZB}, 4=\mathrm{H}+\mathrm{WB}+\mathrm{ZB}$.

GP - total gas produced from MS fermentation after $72 \mathrm{~h}$; DE - degradation efficiency factor;

$\mu$ - the gas at the point of inflection; PF - partitioning factor (mg of substrate degradable/maximum volume of gas); SCFA - short chain fatty acid.

a, b, c, d, e : Numbers with different superscripts in the same row were different $(P<0.05)$.

highest in $\mathrm{H}, \mathrm{ZB}$ and $\mathrm{CS} 1$. System 3 recorded the highest $(P<0.001)$ total SCFA followed by CS 1 , WB and 2 while the rest of the systems $(\mathrm{H}, \mathrm{ZB}$, and 4$)$ were relatively lower. Wildebeest produced a higher total SCFA, which is the main objectives of most digestibility studies, but was even highest when combined with other IS. It is possible to suggest that $\mathrm{H}, \mathrm{WB}$ and $\mathrm{ZB}$ vary in their fibrolytic potential and could be harbouring microbes with different potential, which can be used to create microbial consortia for feed additives application.

\section{Conclusion}

The seven microbial systems were ranked as $1>2>4>\mathrm{H}>\mathrm{ZB}>\mathrm{WB}>3$ and $3>1>4>\mathrm{WB}>2>$ $\mathrm{ZB}>\mathrm{H}$ based on exocellulase activities and fermentation parameters (TP, GP, PF, total SCFA) measured, respectively. This indicates that fibrolytic activity varies among the herbivores and can increase fermentation when combined. It also shows that in vitro transinoculation is possible and could improve rumen fermentation efficiency, rumen fibrolytic microbes' quantity and ecology. Therefore, investigating the in vivo effect of these systems is imperative in our subsequent experimentation to confirm the application of these microbial consortia as feed additives.

\section{Acknowledgement}

We would like to acknowledge National Research Foundation for funding this project and Jessica Moodley for her input and support.

\section{References}

Bänziger, M., Setimela, P.S., Hodson, D. \& Vivek, B., 2006. Breeding for improved abiotic stress tolerance in maize adapted to Southern Africa. Agric.Water Manage. 80, 212-224.

Campos, F.P., Sampaio, A.A.M., Bose, M.L.V., Vieira, P.F. \& Sarmento, P., 2004. Evaluation of in vitro gas production of roughages and their mixtures using the curves subtraction method. Anim. Feed Sci. Technol. 116, 161-172.

Cottyn, B.G. \& Boucque, C.V., 1968. Rapid method for the gas-chromatographic determination of volatile fatty acids in rumen fluid. J. Agric. Food Chem. 16, 105-107.

Dominguez Bello, M.G. \& Escobar, A., 1997. Rumen manipulation for the improved utilization of tropical forages. Anim. Feed Sci. Technol. 69, 91-102. 
Fon, F.N., 2006. Fibrolytic enzyme activity of herbivore microbial ecosystems. MSc. Agric thesis, University of KwaZulu-Natal.

Gado, H.M., Salem, A.Z.M., Robinson, P.H. \& Hassan, M., 2009. Influence of exogenous enzymes on nutrient digestibility, extent of ruminal fermentation as well as milk production and composition in dairy cows. Anim. Feed Sci. Technol. 154, 36-46.

Kenters, N., Henderson, G., Jeyanathan, J., Kittelmann, S. \& Janssen, P.H., 2011. Isolation of previously uncultured rumen bacteria by dilution to extinction using a new liquid culture medium. J. Microbiol. Methods 84, 52-60.

Ouda, J. \& Nsahlai, I., 2009. Relevance and potential use of in vitro gas production measurements to evaluate varying ratios of roughages and protein sources for ruminants. J. Appl. Anim. Res. 35, 9-16.

Pell, A.N. \& Schofield, P., 1993. Computerized monitoring of gas production to measure forage digestion in vitro. J. Dairy Sci. 76, 1063-1073.

Vaithiyanathan, S., Sheikh, Q. \& Kumar, R., 2005. Effect of transinoculation of goat rumen liquor on degradation and metabolism of mimosine in sheep fed with Leucaena leucocephala leaves. AsianAust. J. Anim. Sci. 18, 332-339.

Van Ackeren, C., Steingaß, H., Hartung, K., Funk, R. \& Drochner, W., 2009. Effect of roughage level in a total mixed ration on feed intake, ruminal fermentation patterns and chewing activity of early-weaned calves with ad libitum access to grass hay. Anim. Feed Sci. Technol. 153, 48-59.

Wanapat, M., Pilajun, R. \& Kongmun, P., 2009. Ruminal ecology of swamp buffalo as influenced by dietary sources. Anim. Feed Sci. Technol. 151, 205-214.

Wanapat, W., 2001. Swamp buffalo rumen ecology and its manipulation. Proceedings of Buffalo Workshop. www.mekarn.org/procbuf/wanapat.htm

Wei, H., Xu, Q., Taylor Ii, L.E., Baker, J.O., Tucker, M.P. \& Ding, S.-Y., 2009. Natural paradigms of plant cell wall degradation. Curr. Opin. Biotechnol. 20, 330-338. 